\title{
Structural Equation Modeling for Magnitude, Association and Predictors of Knowledge, Attitude and Practice towards Hepatitis B among Tepi Community, Ethiopia
}

Sunil Tulshiram Hajare ( $\sim$ sunilhajare@gmail.com )

Dilla University

Sebwedin Surur Jemal

Mizan Tepi University

Bizuwork Derebew Alemu

Mizan Tepi University

Nejat Mehammed Aseffa

Jimma University

Misganaw Mola Genet

Mizan Tepi University

Nitin Mahendra Chauhan

Dilla University

\section{Research Article}

Keywords: Hepatitis B Virus, Vaccine, Structural Equation Modeling, Ethiopia

Posted Date: March 2nd, 2022

DOI: https://doi.org/10.21203/rs.3.rs-1365078/v1

License: (c) (i) This work is licensed under a Creative Commons Attribution 4.0 International License.

Read Full License 


\section{Abstract}

Hepatitis B Virus (HBV) infection is a potentially life-threatening liver infection. It also possesses a serious global public health concern. Increasing perception and awareness about HBV helps in reducing the disease burden. However, very little is known about knowledge, attitudes, and practice (KAP) towards HBV infection among university community. Hence, the study is aimed in determining the KAP towards HBV among Tepi campus community. A cross-sectional study was conducted at Tepi campus, Mizan Tepi University, Ethiopia. A total number of 1426 Tepi campus community were selected by simple random sampling. KAP of was assessed using a structured questionnaire. Data were processed in Epi-data 4.6 and exported to STATA 14 and Amos. Structural equation modeling was employed to estimate the relationship among variables. The total response rate was reported to be $100 \%(1426 / 1426)$. Out of the 1426 respondents, $50.60 \%, 68.79 \%$ and $65.68 \%$ were within the poor knowledge, attitude and practice respectively. In structural equation modeling, residence, income and educational level were not associated with mean score. As such, KAP about HBV among Tepi campus community was found to be very poor. In the end, proactive and sustainable efforts are needed among communities to reduce the disease burden caused by HBV.

\section{Introduction}

Infection associated with $\mathrm{HBV}$ is a potentially life-threatening liver infection and a vaccine-preventable infection caused by the HBV, which is a DNA virus classified in the virus family of Hepadnavirida ${ }^{1,2}$. After the virus enters the human body, there is an incubation period on an average of 4 months until illness begins. During the acute phase, most of the persons show symptoms. However, during chronic phase, HBV usually progresses silently, with no symptoms at all during the first 10-20 year ${ }^{3}$. For some of the peoples, HBV infection becomes chronic. Developing chronic hepatitis B increases the risk of developing liver cancer, liver failure or cirrhosis a condition that permanently scars the liver. Most of the adults with HBV infection recover fully, even if the symptoms and signs are severe. Less than $5 \%$ of adult cases become chronically infected by the HBV. Unlike adults, infants and children are more likely to develop a chronic (long-lasting) HBV infection (in about 95\%). If any persons are infected, taking certain precautions can help in reducing the spread of virus to other ${ }^{2,4}$.

HBV can be prevented by vaccines that are safe, available, and effective ${ }^{2}$. But there's no cure if you have the condition ${ }^{4}$. A safe and effective vaccine that offers $98-100 \%$ protection against hepatitis $B$ is available ${ }^{1}$. Thus, preventing HBV averts the development of complications including the development of chronic disease and liver cancer².

Viral hepatitis is a world public health problem affecting several individuals every year, causing disability and death around 300 million individuals chronically infected with hepatitis B virus (HBV) within the world. Approximately 786,000 people die from complications of HBV disease each year ${ }^{5}$. Globally, more than two billion people have been infected with HBV. Of these, about 1.5 million deaths occur from HBV 
related liver diseases, and 350 million people remain infected chronically and become carriers of the virus, including hepatocellular carcinoma and end-stage cirrhosis each year. It was estimated that liver cancer represents approximately $4 \%$ of all new cancer cases diagnosed worldwide and that more than $50 \%$ of liver cancers were attributable to $\mathrm{HBV}^{6}$.

The prevalence of HBV infection varies widely, since 2012, the rates ranged from 0.9-1.1 per 100,000 populations in different parts of the world. The prevalence of HBV is less than one percent in Australia, North America and New Zealand, whereas in Japan it is $2-4 \%$, while in China ranges from $5-18 \%$ but the Asian region its variable with the highest rates in Taiwan $(15-20 \%)^{7}$.

Almost $8 \%$ of this global hepatitis B burden is in Sub-Saharan Africa, with over 80000 new infections of HBV occurring each year. Prevalence of infection varies widely among HBV positive communities: more than $7.4 \%$ in Ethiopia, $8.54 \%$ in Kenya and $8.45 \%$ those in Uganda. About 3.5 million infected individuals and $9.5 \%$ in Senegal affected by HBV ${ }^{8,9}$.

In the study setting, teachers, students and administrative staff can play an important role in order to educate the overall community about HBV infections symptoms, prevention and vaccination. To implement an effective strategy, teachers, students and administrative staff should have a basic understanding of the disease and its various implications on the patients. Several studies suggest that health-related behaviors are affected by knowledge, attitude and practice ${ }^{10,11}$. However, there are no studies examining the KAP level of the Tepi campus community towards HBV infection in Mizan Tepi University. KAP related research have been widely implemented in public health and have been reported to be the most commonly used study tools in health-seeking behavior research ${ }^{12}$.

KAP studies have been used to collect information on what the participants believe, know, and do in relation to a given topi ${ }^{8,10,12,13}$. The knowledge refers to the understanding of symptoms, treatment, and vaccine-related questions ${ }^{14,15}$. Attitude refers to their feelings towards this subject, preconceived ideas that they may have towards it, intention to a particular behavior ${ }^{13-15}$. Practice refers to the ways in which they do their knowledge and attitude through their actions ${ }^{15}$. Therefore, the aim of this study was to examine the KAP towards HBV infection among Tepi campus community, which could help to inform the strategies for prevention and control of HBV infection in the developing country like Ethiopia which are in the widely affected zone of HBV due to lack of relevant information among communities. This work is the first approach to determine the KAP towards the HBV at community level especially in the developing country like Ethiopia, where infection associated with HBV are alarming.

\section{Results}

\section{Socio-demographic Characteristics of the Participants}

A total of 1426 participants with $100 \%$ response rate from the Tepi campus were enrolled during the study. The mean age was 26.99 years (SD = 6.155), and the median age was 26 (IQR: 18 to 49 years). The 
educational status showed that 838 (58.58\%) were attending graduate class while, 346 (18.26\%) were post graduate holder. The majority of those participants were single1362 (95.51\%). In addition, 643 $(45.09 \%)$ of them were found to be student (Table 1).

Table 1

Socio-demographic characteristics of the study participants from Tepi community, Mizan Tepi University, Ethiopia

\begin{tabular}{|llll|}
\hline Variable & Categories & Frequency & Percent (\%) \\
\hline Sex & Male & 1279 & 89.69 \\
& Female & 147 & 10.31 \\
\hline Age & $18-25$ & 548 & 38.43 \\
& $26-35$ & 750 & 52.59 \\
& $36-46$ & 110 & 7.71 \\
Marital status & S6-49 & 18 & 1.26 \\
& Single & 1362 & 95.51 \\
& Married & 41 & 2.88 \\
& Divorced & 20 & 1.40 \\
& Widowed & 3 & 0.21 \\
\hline Occupation & Student & 643 & 45.09 \\
& Teacher & 264 & 18.51 \\
& Administrative & 519 & 36.40 \\
\hline Educational status & Diploma and lower & 272 & 19.07 \\
& Undergraduate & 838 & 58.53 \\
& Postgraduate & 346 & 18.26 \\
\hline
\end{tabular}

\section{Knowledge Related Characteristics towards HBV}

Less than one fourth i.e. 228 (15.99\%) of the study participants heard of a disease termed as hepatitis B. The majority of respondents i.e. $886(62.02 \%)$ believed that HBV cannot cause liver cancer. Of the study participants, $540(37.80 \%)$ were believed that early symptoms of Jaundice is one of the common symptoms of HBV infection. Study participants were asked to give their perception on about nausea; vomiting and loss of appetite are common symptom of HBV infection. Most of the participants i.e. 757 (53.09\%) reported that they are symptom of HBV. 710 (49.79\%) reported that HBV can be transmitted by unsafe sex and 844 (59.19\%) suggest that no specific diet required for treatment (Table 2). 
Table 2

Knowledge related characteristics of study participants towards HBV from Tepi community, Mizan Tepi University, Ethiopia

\begin{tabular}{|c|c|c|c|}
\hline Variable & Categories & Frequency & $\begin{array}{l}\text { Percent } \\
\text { (\%) }\end{array}$ \\
\hline \multirow[t]{2}{*}{ Have you heard of a disease termed as Hepatitis? } & Yes & 228 & 15.99 \\
\hline & No & 1198 & 84.01 \\
\hline \multirow[t]{2}{*}{ Is hepatitis B a viral disease? } & Yes & 543 & 61.92 \\
\hline & No & 883 & 38.08 \\
\hline \multirow[t]{2}{*}{ Can hepatitis B affect liver function? } & Yes & 540 & 37.87 \\
\hline & No & 886 & 62.13 \\
\hline The early symptoms of Hepatitis B & Yes & 539 & 37.80 \\
\hline Jaundices one of the common symptoms of Hepatitis B? & No & 887 & 62.02 \\
\hline \multirow{2}{*}{$\begin{array}{l}\text { Are nausea, vomiting and loss of appetite common symptom } \\
\text { of hepatitis B? }\end{array}$} & Yes & 757 & 53.09 \\
\hline & No & 669 & 46.91 \\
\hline \multirow{2}{*}{$\begin{array}{l}\text { Can Hepatitis B transmitted by unsterilized syringe needle and } \\
\text { surgical instrument? }\end{array}$} & Yes & 263 & 18.50 \\
\hline & No & 1159 & 81.50 \\
\hline \multirow{2}{*}{$\begin{array}{l}\text { Can Hepatitis B transmitted by contaminated Blood and Blood } \\
\text { product? }\end{array}$} & Yes & 887 & 62.20 \\
\hline & No & 539 & 37.79 \\
\hline \multirow[t]{2}{*}{ Can Hepatitis B transmitted by unsafe sex? } & Yes & 710 & 49.79 \\
\hline & No & 716 & 50.21 \\
\hline \multirow[t]{2}{*}{ Can Hepatitis B transmitted by mother to child? } & Yes & 693 & 48.60 \\
\hline & No & 733 & 51.40 \\
\hline \multirow[t]{2}{*}{ Is Hepatitis B curable/treatable? } & Yes & 857 & 60.10 \\
\hline & No & 569 & 39.90 \\
\hline \multirow[t]{2}{*}{ Can Hepatitis B self-cured by body? } & Yes & 823 & 59.82 \\
\hline & No & 573 & 40.18 \\
\hline \multirow[t]{2}{*}{ Is vaccination available for Hepatitis B? } & Yes & 866 & 60.73 \\
\hline & No & 560 & 39.27 \\
\hline \multirow[t]{2}{*}{ Is specific diet required for treatment of Hepatitis $B$ ? } & Yes & 844 & 59.19 \\
\hline & No & 582 & 40.81 \\
\hline
\end{tabular}




\section{Attitude related factors towards HBV}

The majority of the respondent i.e. 786 (55.16\%) believed that they can get infected with HBV. 640 $(63.1 \%)$ respondents stated that they will not go to anywhere if they get infected with HBV, 256 (17.95\%) worried isolation from the community. Whereas, $742(47.72 .6 \%)$ of them will referred to health facility as soon as they realized the symptoms of HBV (Table 3 ). 
Table 3

Attitude related responses among participants towards HBV from Tepi community, Mizan Tepi University, Ethiopia

\begin{tabular}{|c|c|c|c|}
\hline Variable & Categories & Frequency & $\begin{array}{l}\text { Percent } \\
\text { (\%) }\end{array}$ \\
\hline \multirow[t]{2}{*}{ Do you think you can get Hepatitis B? } & Yes & 786 & 55.16 \\
\hline & No & 639 & 44.84 \\
\hline \multirow{5}{*}{$\begin{array}{l}\text { What would be your reaction if you found that you have } \\
\text { Hepatitis B? }\end{array}$} & Fear & 107 & 7.5 \\
\hline & Shame & 68 & 13.7 \\
\hline & Surprise & 127 & 25.6 \\
\hline & Sadness & 139 & 28 \\
\hline & Health facility & 101 & 20.3 \\
\hline \multirow[t]{2}{*}{ Do you have Hepatitis B? } & Yes & 562 & 39.41 \\
\hline & No & 864 & 60.59 \\
\hline \multirow[t]{2}{*}{ Who would you talk to about your illness? } & Physician & 142 & 28.6 \\
\hline & Spouse & 355 & 71.4 \\
\hline \multirow{4}{*}{$\begin{array}{l}\text { What will you do if you think that you have symptoms of } \\
\text { Hepatitis B? }\end{array}$} & Go to health & 742 & 47.72 \\
\hline & Go to physician & 285 & 18.09 \\
\hline & $\begin{array}{l}\text { Not got any } \\
\text { where }\end{array}$ & 314 & 22.02 \\
\hline & $\begin{array}{l}\text { Go to } \\
\text { traditional } \\
\text { healer }\end{array}$ & 112 & 7.85 \\
\hline \multirow{3}{*}{$\begin{array}{l}\text { If you had symptoms of Hepatitis B, at what stage you } \\
\text { will go to the health facility? }\end{array}$} & Own treatment & 313 & 21.95 \\
\hline & ? & 300 & 21.04 \\
\hline & Soon as I & 500 & 35.06 \\
\hline \multirow{5}{*}{$\begin{array}{l}\text { What worries you most if you will be diagnosed with } \\
\text { Hepatitis B? }\end{array}$} & Fear of death & 402 & 28.19 \\
\hline & $\begin{array}{l}\text { Spread of } \\
\text { family }\end{array}$ & 256 & 17.95 \\
\hline & Cost of & 512 & 35.91 \\
\hline & treatment & 256 & 17.95 \\
\hline & Isolation & & \\
\hline
\end{tabular}


Majority of the respondents,873 (61.22\%) had never screened for HBV and 869 (60.94\%) stated that they got vaccinated against HBV. 828 (58.23\%) and 989 (69.35\%) never asked for a new syringe, screening of blood before transfusion respectively while, majority of the respondent $731(51.26 \%)$ agreed with that they avoid meeting a person infected with HBV and majority of the study participants i.e. 768 (53.86\%) were ready go for further investigation and treatment if they are infected with HBV. In addition, a highest number of respondent's i.e.731 (51.33\%) has never attended any educational program on HBV (Table 4).

Table 4

Practice related characteristics of study participants towards HBV from Tepi community, Mizan Tepi University, Ethiopia

\begin{tabular}{|llll|}
\hline Variable & Categories & Frequency & $\begin{array}{c}\text { Percent } \\
\text { (\%) }\end{array}$ \\
\hline Have you done screening for Hepatitis B? & Yes & 553 & 38.78 \\
\hline Have you got yourself vaccinated against Hepatitis B? & No & 873 & 61.22 \\
\hline Do you ask for a new syringe before use? & Yes & 869 & 60.94 \\
\hline Do you ask for screening of blood before transfusion? & No & 557 & 39.06 \\
\hline $\begin{array}{l}\text { In case you are diagnosed with Hepatitis B, would you go for } \\
\text { further investigation and treatment? }\end{array}$ & Yes & 594 & 41.77 \\
\hline Do you avoid meeting Hepatitis B patients? & No & 828 & 58.23 \\
\hline Have you ever participated in health education program related & Yes & 437 & 30.65 \\
\hline to Hepatitis B? & No & 658 & 69.35 \\
\hline
\end{tabular}

\section{Knowledge, Attitude and Practice related Factors towards HBV}

Out of the 1426 participants, majority of the respondents i.e. 722 (50.60\%) were within the poor knowledge range with the mean and SD level of $7.24 \pm 2.83$ whereas, $628(44.06 \%)$ showed moderate knowledge about HBV. However, small number of participants has enough knowledge about HBV.

As shown in the Fig. 1, 936 (65.68\%) of those participants with negative practice towards HBV, which was relatively higher percent when compared to having good practice and moderate level of practice. Those 
with moderate level of practice participant's relatively possess higher percent when compared to having food level of practice.

Majority of the respondents respondent 981 (68.79\%) were within the poor attitude towards HBV. Which is range with the mean and SD level of $2.51 \pm 1.62$ whereas, 628 (44.06\%) showed moderate attitude about HBV. Still small number of participants has enough attitude towards HBV (Fig. 1).

In the fitted model (Fig. 1), the majority of path co-efficient in the diagram was statistically significantly at $5 \%$ level of significant. Accordingly, the model included exogenous variables like age and educational level, 12 knowledge related variables, 8 attitude related variables and practice related variables. 2 exogenous variables (age and educational level) were both indirectly and directly related with KAP via the mediator variables.

\section{Test of the goodness of fit of the hypothetical model}

The results of the analysis of the structural equation model produced using the study variables in the hypothetical model were as follows: goodness of fit test $(P<0.05, d f=48), C F I=0.941$, RMSEA $=0.042$, $\mathrm{NFI}=0.812, \mathrm{GFI}=0.901, \mathrm{RMR}=0.055$, and PNFI $=0.42$ (Table 5). All of the GFI indices indicated they are satisfied as shown in Table 5. Thus, the hypothesized model for KAP towards HBV had a good fit and is acceptable. The structural model between the socio-demographic factor and domain of knowledge, attitude and practices towards HBV is shown in Figure S3.

Table 5

Goodness of fit indices

\begin{tabular}{|l|lc|}
\hline $\boldsymbol{x} \mathbf{2} / \mathbf{d f}$ & $\mathbf{2 . 5 2}$ & $<\mathbf{3}$ \\
\hline Comparative Fit Index (CFI) & 0.941 & $>0.90$ \\
\hline Goodness of Fit Index (GFI) & 0.902 & $>0.90$ \\
\hline Root Mean Square Error of Approximation (RMSEA) & 0.042 & $<0.10$ \\
\hline Normed Fit Index (NFI) & 0.812 & $>0.90$ \\
\hline Root Mean Square Residual (RMR) & 0.054 & $<0.08$ \\
\hline
\end{tabular}

The direction and extent of relationships of knowledge and attitude towards HBV and their direct effects on the practices model is shown in Table 6. Knowledge about HBV has a positive and significant relationship ( $\beta 1=0.0924 ; P=-0.33$ which is less than 0.05 ) with community practices towards HBV so we fail to reject hypothesis 1 . The findings clearly indicate that knowledge about HBV directly affects practices of the community towards HBV. Based on the magnitude (i.e. $\beta 1=-0.284 ; P>0.05$ ) and direction (i.e. positive relationship) of the model, practices of the community towards HBV will possibly increase by 0.0924 units with each unit increase in knowledge. The second hypothesis postulates that attitude directly affects practices of the community towards HBV. HBV attitude and practice are sustained 
as the SEM demonstrates a positive and significant relationship between the two variables $(\beta 1=0.22 ; P=$ 8.27e-10) (Table 6). There is an insignificant relationship between HBV knowledge and attitude in this study $(\beta 1=0.005 ; P>0.05)$ thus it is rejected as shown in Table 7. 
Table 6

Indirect, direct and total effect of socio-demographic and KPA related factors towards HBV from Tepi community, Mizan Tepi University, Ethiopia

\section{Characteristics Direct Effect (95\% Cl); Indirect effect (95\% Cl); Total Effect (95\% Cl) DV: Dependent Variable}

Practice 000

Knowledge 0.092357 .03110232 .970 .003 .0313977 .1533163

Attitude 0.2200664 .03587716 .130 .000 .1497487 .2903842

DV Knowledge domain

k15 000

age $<--0.0587092 .041706-1.410 .159-.1404514 .023033$

$\mathrm{k} 1<-0.0337253 .0232311 .450 .147-.0118066 .0792572$

k2 <- $0.044878 .03068621 .460 .144-0152658.1050218$

k3 <- $0.0148465 .0306570 .480 .628-.0452402 .0749332$

k4 < - 0.0631882 .03072712 .060 .040 .0029642 .1234122

k5 <- $0.061363 .03174351 .930 .053-0008531.1235792$

k6 < - $0.011809 .02460360 .480 .631-0364132.0600312$

k7 < - 0.1994665 .03143846 .340 .000 .1378483 .2610846

k8 < - 0.0840375 .0324692 .590 .010 .0203993 .1476756

k9 <- 0.1292775 .03260673 .960 .000 .0653695 .1931856

k10 <- 0.0638946 .03101562 .060 .039 .0031052 .1246841

k11<- 0.1837986 .03178165 .780 .000 .1215077 .2460894

k13 - 0.239089 .03138767 .620 .000 .1775704 .3006076

k14 <- 1.007177 .032385631 .100 .000 .94370231 .070652

DV Practice domain

P8 000

P1 <- 0.1610399 .03304974 .870 .000 .0962637 .2258161

P2 <- $0.0586927 .03304421 .780 .076-.0060727 .1234581$

P3 <- 0.2239752 .03764175 .950 .000 .1501989 .2977516

P4 <- $0.0360087 .03050661 .180 .238-0237831.0958004$ 


\begin{tabular}{|l|}
\hline Characteristics Direct Effect $(95 \% \mathrm{Cl})$; Indirect effect $(95 \% \mathrm{Cl})$; Total Effect $(95 \% \mathrm{Cl})$ \\
DV: Dependent Variable \\
\hline P5 $<-0.8959817 .043310620 .690 .000 .8110945 .9808688$ \\
\hline P6 $<-0.1702566 .03550094 .800 .000 .1006761 .2398372$ \\
\hline P7 $<-0.1015536 .03376133 .010 .003 .0353826 .1677246$ \\
\hline DV Attitude domain \\
\hline A1 000 \\
\hline edu<- $0.1324032 .0846813-1.560 .118-.2983755 .0335691$ \\
\hline A2 $<-0.0051662 .01884170 .270 .784-.0317629 .0420953$ \\
\hline A3 $<-1.150448 .030618137 .570 .0001 .0904381 .210459$ \\
\hline A4 $<-0.0354706 .03971180 .890 .372-.0423631 .1133043$ \\
\hline A5 $<--0.0097031 .0294468-0.330 .742-.0674177 .0480115$ \\
\hline A6 $<-1.147406 .030799237 .250 .0001 .0870411 .207772$ \\
\hline A7 $<-0.0061791 .03193730 .190 .847-.0564169 .0687751$ \\
\hline
\end{tabular}

Table 7

Relationship among KAP towards HBV

\begin{tabular}{|llll|}
\hline Paths & Estimate & $P$ value & Standard error \\
\hline Knowledge $\rightarrow$ Practice & 0.093 & 0.0034 & 0.031 \\
\hline Attitude $\rightarrow$ Practice & 0.22 & $8.27 \mathrm{e}-10$ & 0.032 \\
\hline Knowledge $<->$ Attitude & 0.0095 & 0.0595 & 0.0294 \\
\hline
\end{tabular}

\section{Discussion}

The current study evaluates the role of KAP towards HBV among Tepi campus community from Mizan Tepi University, Ethiopia. Results of the study revealed poor knowledge, attitude and practice towards HBV. The mean knowledge score was $7.24 \pm 2.83$ indicating low level of knowledge towards HBV and the mean attitude score was $2.51 \pm 1.62$ indicating negative attitude towards HBV. This lack of knowledge and attitude may influence the practice of the respondents towards interventions and prevention that could reduce the risk of disease transmission.

The results of the findings show that $50.06 \%$ of the respondents had poor knowledge, whereas, another study conducted in China in 2017 showed that $21 \%$ of participants were able to answer all the general knowledge-related questions correctly ${ }^{17}$. Similarly, a study conducted in Ghana showed that less than 
half of the participants (46.2\%) knew about HBV ${ }^{18}$. Moreover, a study conducted in the Buea Health District, Cameroon reported that less than $20 \%$ of the participants had good knowledge about HBV ${ }^{19}$. On the other hand, in a study conducted in Addis Ababa, below half of the respondent (39.2\%) had adequate knowledge about $\mathrm{HBV}^{20}$.

According to our result where measures towards HBV depend on whether people hear about hepatitis, only $15.99 \%$ of the respondents hear about HBV, $62.20 \%$ of respondents aware that HBV is can be transmitted by contaminated blood and blood products, $49.79 \%$ through unsafe sex, and $48.60 \%$ through vertical transmission (from mother to child during pregnancy) (Table 2). This is in line with a study conducted by ul Haq et al. from Pakistan ${ }^{21}$ and Bayuh from Addis Ababa, Ethiopia ${ }^{20}$. Lack of knowledge about HBV transmission and prevention can be attributed in increasing the risk and the frequency of HBV in the population at all. This is particularly important in the view that adults in Tepi town have poor education on HBV virus transmission, prevention and available services despite radio talk shows among community can outreaches to overcome HBV outbreak. On contrary, a study conducted in Nigeria in 2015 showed that $72.9 \%$ of the respondents know that HBV transmitted from mother to child 22 and a study conducted in Vietnam showed that $75.3 \%$ of the participants were aware that HBV is transmitted through unprotected $\operatorname{sex}^{23}$. Condoms can act as major barrier for preventing sex transmitted diseases and hence, implying awareness campaign will help to promote condom use as a major preventive message for HBV prevention among communities ${ }^{23,24}$.

Results of our study predicted that, only $37.87 \%$ of our study participants believed that HBV can cause liver cancer; similarly, low level of knowledge was reported from Japan $(18.5 \%)^{24}$, from Pakistan $(28.2 \%)^{25}$ and from Gondar comprehensive specialized hospital, northwest Ethiopia, which is $28.5 \% 26$. However, it contradicts findings of Wah et al. from China who found that $87 \%$ of the study participants believed that HBV can cause liver cancer ${ }^{17}$. Such lack of knowledge is considered to be serious since, it is one of the easiest ways of transmission of HBV27.

In our study, 5.34\% of the respondents had positive attitude towards HBV. Our study has very high difference with the studies conducted in Honiara, Solomon Islands $(35.3 \%)^{28}$ and a study conducted in Gondar comprehensive specialized hospital, Northwest Ethiopia ${ }^{26}$. In addition, a study conducted in Bangladesh showed that $50 \%$ of study participants had positive attitude towards $\mathrm{HBV}^{29}$. This difference may have been brought due to difference in study population, study design, population size and sampling technique.

According to our study, $5.45 \%$ of study participants had good practice. This is very lower than a study conducted in Honiara, Solomon Islands, which showed that $26.3 \%$ of study participants had good practice $^{28}$ and the study conducted in Gondar comprehensive specialized hospital, northwest Ethiopia ${ }^{13}$. But a high rate of good practice towards HBV was reported by Bayuh from Addis Ababa (42.7\%) ${ }^{20}$. In our study, $61.22 \%$ had not screened for HBV, while a study conducted in China in 2017 showed that $68.5 \%$ of study participants had not screened ${ }^{17}$. This differences was due to limited availability of healthcare, low 
awareness towards the availability of vaccines, unknowing the importance of screening for HBV prevention and control, and educational status of the participant in Tepi town.

Area of residence, unable to read and write, and income were insignificantly associated with mean KAP scores. In contrast, the study conducted by ul Haq et al. from Pakistan ${ }^{21}$, Cheung et al. in 2005 among Chinese and South Asian Canadians ${ }^{30}$, and Wu et al. in 2007 among Americans ${ }^{31}$. In contrast, reports from Addis Ababa, Ethiopia ${ }^{20}$ and Guangdong Province, China ${ }^{17}$, showed that higher education level was associated with better knowledge and attitude scores.

Health workers play an important role in both public health and community health when it comes to combat the spread of HBV by spreading information on protective measures, such as vaccination and information about the transmission of the disease ${ }^{32}$. The supply of educated and informed health care workers is therefore crucial to minimize the consequences acquired through HBV infection.

In the end, the overall knowledge of the participants was found to be poor and their attitude and practice towards HBV were also limited. In this study, most of the participants had poor knowledge about the symptom, transmission and prevention of hepatitis B. Moreover, most were not vaccinated due to lack of knowledge about the presence of HBV vaccine in the study area. The KPA of HBV was not associated with any one of socio-demographic characteristics, suggesting that any effort to increase knowledge and attitude may improve individuals' negative practice towards HBV.

Inadequate knowledge is probably an important factor in HBV infection, $138(60.8 \%)$ of the study participants were within the poor knowledge, since those with better knowledge were more likely to be tested for HBV. According to these findings there is a lack of understanding of the basics of infection prevention and control of transmission of HBV. The structural equation modeling showed a good fit on knowledge, attitude and practice about HBV. Within SEM, although respondents are generally having moderate knowledgeable about HBV, this translate directly into practices of HBV. And also, attitude has been identified as a significant factor in influencing practices of HBV. An insignificant relationship between knowledge and attitude suggests that the attributes affect practices of HBV independently. Good practices, good knowledge and good attitude toward HBV play a critical role in protecting individuals and households from HBV, contribute to an overall improved social and quality of life and reduce the incidence of HBV.

\section{Methodology}

\section{Study Settings}

An institution based cross-sectional study was conducted from October to December 2021 at Tepi campus of Mizan-Tepi University, Ethiopia which is approximately $611 \mathrm{~km}$ far from Addis Ababa towards southwest direction. The study place is located at a mean elevation of 1,097 meters above sea level at latitude of $7^{\circ} 12^{\prime} \mathrm{N}$ and longitude of $35^{\circ} 27^{\prime} \mathrm{E}$ (Figure S1). The study was conducted among Tepi campus 
staff members, teachers and students who were settled one year and above in Tepi town. The campus has served more than 7 thousand people (staff members, teachers and students) and people of the neighboring city. The campus consists of college of natural and computational science, school of computing, engineering and technology and many more departments.

\section{Study Population, Sample Size, and Sampling Technique.}

All Tepi campus teachers, administrative staffs and one year and above students were referred for data collection throughout the study. The number of free parameters to be estimated excluding those factor loadings (path coefficients) fixed to unity 1 , which is three in our case, there are 118 free parameters to be estimated such as all regression coefficients between observed exogenous variables or latent variables (54 in our case), all factor loadings on indicator variables except those paths fixed to 1 ( 27 in our case), all variances of independent variables (31 error variances in our case) and all covariance between independent variables ( 6 error covariance in our case) yielding a total of 118 parameters to be estimated. Thus, degree of freedom is calculated as number of available inputs minus number of free parameters to be estimated which is equal to $446-118=328$. This implies that the above model is structurally identified, specifically it is over-identified model. Using 1:10 ratio of respondents to free parameters to be estimated has been recommended ${ }^{16}$. Accordingly, considering the 118 free parameters to be estimated based on the hypothesized model, taking participants to free parameters ratio of 20 and a non-response rate of $10 \%$, the required minimum sample size is estimated to be 1475 .

Final sample size $\left(n_{f}\right)=$ Effective sample size $\left(n_{o}\right) /(1-$ non response rate anticipated)

$$
\begin{gathered}
n_{f}=\frac{n_{o}}{(1-\text { non response rate })} \\
n_{f}=\frac{1180}{(1-0.2)}=\frac{1180}{0.8} \\
n_{f}=1475
\end{gathered}
$$

Finally, total sample size allocates proportionally for Tepi campus community using stratification and simple random sampling technique was employed to withdraw samples from study population. Thus, studied sample size constitutes 783 students, 181 teachers and 462 administrative staffs which is in sum equal to 1426 samples. All methods followed were performed in accordance with the relevant guidelines and regulations as stated in the ethics form. 


\section{Data Collection Tool and Technique}

Socio-demographic characteristics like sex, educational background, residence, age and occupation and other variables related to KAP like source of information, accessibility of health service, screening for HBV, availability of vaccine, and sharing of needles and blades were collected using a pretested structured questionnaire.

\section{Data Quality control and Assurance}

Initially a semi-structured questionnaire was prepared in English version, then translated into Amharic (local language) and translated back in to English by another person to check the consistence. Next, it was pre-tested for its accuracy, completeness, and consistency prior to actual collection on five percent of the sample population Tepi Campus. The questionnaire was rechecked by principal investigators for its completeness, accuracy and clarity of the collected data carefully and any error was addressed and resolved.

\section{Data Analysis}

The returned data were arranged and organized in to meaningful ways and data were coded and entered into Epi Data 4.6 statistical packages and then exported to STATA version 14. Categorical variables were calculated as percentages while, continuous variables were expressed as mean \pm standard deviation. Reliability was also assessed for each domain of KPA using the Cronbach's a coefficient and values of 0.7 or higher were considered as satisfactory. The score of each domain of KPA was obtained by averaging their corresponding items for each participant. Knowledge was assessed by questions related with HBV, symptoms and sign, treatment and transmission. Each response was scored as "yes" or "no." The scoring range of the questionnaire was 1 to 15 . A cutoff level $\leq 7.5$ was considered poor whereas, $>7.5$ was quoted as adequate knowledge about HBV. Knowledge scores for individuals were measured and were added to give up the total knowledge score.

Practices towards HBV were assessed by asking 8 questions as listed in Table 4. Each question was labeled with good, moderate or poor practice. A score of 1 was given to good while, 0 was considered as bad practice with a score range of 0 to 8 . The scale classified practice as positive with score $>4$ and negative for $\leq 4$.

The Structural Equation Modeling (SEM) was employed to examine the relationship between various dependent and independent or mediating variables. Structural equation modeling (SEM) is a confirmatory, multivariate technique that looks at causal relationships between variables in a diagrammatic form. Because KPA and its domain were latent variables which constitute items with ordered responses, their measurement model was analyzed using SEM because multivariate normality assumption was satisfied ${ }^{16}$. The analysis was started with the hypothesized model (Figure S2) and 
modification were performed iteratively by adding path links or including mediator variables, if theoretically supported and Root Mean Square Error (RMSE) as well as comparing the Comparative Fit Index (CFI) of approximation RMSE of each model fitted. Finally, an over identified model with value RMSE $<0.05$ and $\mathrm{CFI}>=0.95$ was retained. Diagrammatically, the effect of each exogenous or mediating variable on the respective dependent variable was represented by the path coefficient along with single headed arrow and the correlation among disturbances (residual errors that reflect the unexplained variances in the latent endogenous variables due to all unmeasured causes) was indicated by double arrows. When mediation of effects was present, the direct, indirect and total effects were determined using the non-linear combination of estimator technique. The final model (Figure S3) that that fitted the data well and appeared theoretically meaningful was built by analyzing the hypothesized model (Figure S2) and inspecting iteratively the statistical significance of path coefficients and the relevance of relationships in the model.

\section{Ethical Consideration}

Ethical approval was obtained from Mizan Tepi university institutional review board. Permission was obtained from the Tepi campus, Mizan Tep University, Ethiopia. The reason for conducting and importance of the study was explained to each study participant. Written consent was obtained from all the participants. Apart from these, all respondents were asked to fill out the questionnaire.To adequate the confidentiality of participant's information and knowledge, anonymous typing was used whereby, names of the participants and any other identifiers were excluded from the questionnaire. All the data gathered were stored in the computer through secured password. Only principle investigator and research members are permitted to access the data throughout the work.

\section{Operational Definition}

Knowledge: Information stored in memory assessed in terms of what the participants know about HBV.

Knowledgeable: Study participants who correctly answered greater than or equal to $70 \%$ of knowledgerelated questions.

Not knowledgeable: Study participants who answered less than $70 \%$ of knowledge-related questions.

Attitude: Complex interaction of beliefs, feelings and values to respond in a manner towards HBV.

Positive attitude: Study participants who answered correctly greater than or equal to $70 \%$ of the attituderelated questions about HBV.

Negative attitude: Study participant who answered less than $70 \%$ of the attitude-related questions about HBV. 
Practice: What the respondents actually practice for prevention and control of HBV.

\section{Data availability}

All data generated or analysed throughout the study is fully available in this article. However, complete dataset can be accessed from corresponding author upon reasonable request.

\section{Declarations}

\section{Author contributions}

Concept, designing and coordinating the research: STH, NMC, MMG; Conducted the study and analyzed the data: SSJ, BDA, MMG; Questionnaire design and analysis: MMG, NMA; Manuscript drafting: STH, MMG, NMA; Review and editing: NMC; All authors read and finally agree to approve the manuscript.

\section{Competing of Interests}

The Authors states that they don't have any conflict of interest.

\section{References}

1. Emerenini, B. O. \& Inyama, S. C. Mathematical model and analysis of hepatitis B virus transmission dynamics. F1000 Research. 7, 1312 (2018).

2. Palayew, A., Razavi, H., Hutchinson, S. J., Cooke, G. S. \& Lazarus, J. V. Do the most heavily burdened countries have the right policies to eliminate viral hepatitis B and C? Lancet Gastroenterol Hepatol. 5, 948-953 (2020).

3. Zhang, L. \& Wilson, D. P. Trends in notifiable infectious diseases in China: implications for surveillance and population health policy. PLoS One. 7, e31076 (2012).

4. Chen, C. Y. \& Panebianco, A. Physical and psychological conditions of parental chronic illness, parentification and adolescent psychological adjustment. Psychol Health. 35, 1075-1094 (2020).

5. Ogundeji, A. A. Sero-prevalence of Human Immunodeficiency Virus, Hepatitis B, Hepatitis C, Syphilis and Co-Infections among Antenatal Women: A Retrospective Case Study at National Hospital Abuja, Federal Capital Territory (FCT), Nigeria. Texila Int. J. Public Heal. 6, 1-8 (2018).

6. Lavanchy, D. Hepatitis B virus epidemiology, disease burden, treatment, and current and emerging prevention and control measures. J Viral Hepat. 11, 97-107 (2004).

7. Sinha, S. \& Kumar, M. Pregnancy and chronic hepatitis B virus infection. Hepatol Res. 40, 31-48 (2010).

8. WHO. Guidelines for the prevention care and treatment of persons with chronic hepatitis B infection: March-2015. (2015). 
9. Abebe, A., Nokes, D. J., Dejene, A., Enquselassie, F., Messele, T. \& Cutts, F. T. Seroepidemiology of hepatitis B virus in Addis Ababa, Ethiopia: transmission patterns and vaccine control. Epidemiol Infect. 131, 757-70 (2003).

10. WHO, UNODC, UNAIDS. Technical guide for countries to set targets for universal access to HIV prevention, treatment and care for injecting drug users-2012 revision. (2012).

11. WHO. Guidance on prevention of viral hepatitis B and C among people who inject drugs. (2012).

12. Perz, J. F., Armstrong, G. L., Farrington, L. A, Hutin, Y. J. F. \& Bell, B. P. The contributions of hepatitis B virus and hepatitis $C$ virus infections to cirrhosis and primary liver cancer worldwide. $J$ Hepatol. 45, 529-38 (2006).

13. Demsiss, W., Seid, A. \& Fiseha, T. Hepatitis B and C: Seroprevalence, knowledge, practice and associated factors among medicine and health science students in Northeast Ethiopia. PLoS One. 13, e0196539 (2018).

14. Hamadah, R., Kharraz, R., Alshanqity, A., AlFawaz, D., Eshaq, A. M. \& Abu-Zaid, A. Hand Hygiene: knowledge and attitudes of fourth-year clerkship medical students at Alfaisal University, College of Medicine, Riyadh, Saudi Arabia. Cureus. 7, e310 (2015).

15. Mekonnen, A., Desta, K. \& Damtew, E. Prevalence of HBV, HCV and associated risk factors among cleaners at selected public health centers in Addis Ababa, Ethiopia. Int J Basic App/ Virol. 4, 35-40 (2015).

16. Cornelius, L. J. \& Harrington, D. A social justice approach to survey design and analysis. Oxford University Press, USA. (2014).

17. Han, Z., Yin, Y., Zhang, Y., Ehrhardt, S., Thio, C. L., Nelson, K. E., et al. Knowledge of and attitudes towards hepatitis $B$ and its transmission from mother to child among pregnant women in Guangdong Province, China. PLoS One. 12, e0178671 (2017).

18. Webb, M. J., Kauer, S. D., Oze,r E. M., Haller, D. M. \& Sanci, L. A. Does screening for and intervening with multiple health compromising behaviours and mental health disorders amongst young people attending primary care improve health outcomes? A systematic review. BMC Fam. Pract. 17, 1-12 (2016).

19. Fomulu, N. J., Morfaw, F. L. I., Torimiro, J. N., Nana, P., Koh, M. V. \& William, T. Prevalence, correlates and pattern of Hepatitis $\mathrm{B}$ among antenatal clinic attenders in Yaounde-Cameroon: is perinatal transmission of HBV neglected in Cameroon? BMC Preg. Childbirth. 13, 1-10 (2013).

20. Bayuh F. Prevalence of Hepatitis B Surface Antigen and KAP towards HBV Infection, among Pregnant Women Attending Selected Antenatal Clinics in Addis Ababa, Ethiopia. M. Sc. Thesis, Addis Ababa University, Addis Ababa, Ethiopia, 2014.

21. Nygaard, V., Løland, A.,, Holden M., Langaa,s M., Rue, H., Liu, F., et al. Effects of mRNA amplification on gene expression ratios in cDNA experiments estimated by analysis of variance. BMC Genomics. 4, 1-13 (2003).

22. Gboeze, A. J., Ezeonu, P. O., Onoh, R. C., Ukaegbe, C. I. \& Nwali, M. I. Knowledge and awareness of hepatitis B virus infection among pregnant women in Abakaliki Nigeria. J Hepat Res. 2, 1029 (2015). 
23. Hang Pham, T. T, Le, T. X., Nguyen, D. T., Luu, C. M., Truong, B. D., Tran, P. D., et al. Knowledge, attitudes and practices of hepatitis $B$ prevention and immunization of pregnant women and mothers in northern Vietnam. PLoS One. 14, e0208154 (2019).

24. Eguchi, H. \& Wada, K. Knowledge of HBV and HCV and individuals' attitudes toward HBV-and HCVinfected colleagues: a national cross-sectional study among a working population in Japan. PLoS One. 8, e76921 (2013).

25. Wah, C. P., Hung, S. S., Ka, C. O., His, L. T. \& Yeung, L. T. Awareness and knowledge of hepatitis B infection and prevention and the use of hepatitis $B$ vaccination in the Hong Kong adult Chinese population. Chin Med J (Engl). 125, 422-427 (2012).

26. Gebrecherkos, T., Girmay, G., Lemma, M. \& Negash, M. Knowledge, attitude, and practice towards Hepatitis B virus among pregnant women attending antenatal care at the University of Gondar comprehensive specialized hospital, Northwest Ethiopia. Int J Hepatol. 2020, 5617603 (2020).

27. World Health Organization. Hepatitis B. Collected 9th of January, 2013, from http://www.who.int/mediacentre/factsheets/fs204/en/index.html. (2012)

28. Islands S. Second generation surveillance of antenatal women and youth. Ministry of Health, Solomon Islands, Secretariat of the Pacific Community (SPC). (2008).

29. Rahman, M. A. \& Mannan, S. R. The knowledge, attitude and practices regarding HBV infection of married women in the reproductive age group living in different districts of Bangladesh. Med Today. 22, 29-31 (2010).

30. Cheung, J., Lee, T. K., The, C. Z., Wang, C. Y. M., Kwan, W. C. \& Yoshida, E. M. Cross-sectional study of hepatitis B awareness among Chinese and Southeast Asian Canadians in the Vancouver-Richmond community. Can J Gastroenterol. 19, 245-249 (2005).

31. Wu, C. A., Lin, S. Y., So, S. K. \& Chang, E. T. Hepatitis B and liver cancer knowledge and preventive practices among Asian Americans in the San Francisco Bay Area, California. Asian Pac J Cancer Preven. 8, 127-134 (2007).

32. International Council of Nurses. The ICN code of ethics for nurses. Geneva: International Council of Nurses. Accesed 9th of January, 2013 from http://www.icn.ch/images/stories/documents/publications/free_publications/Code_of_Ethics_ 2012.pdf. (2012).

\section{Figures}




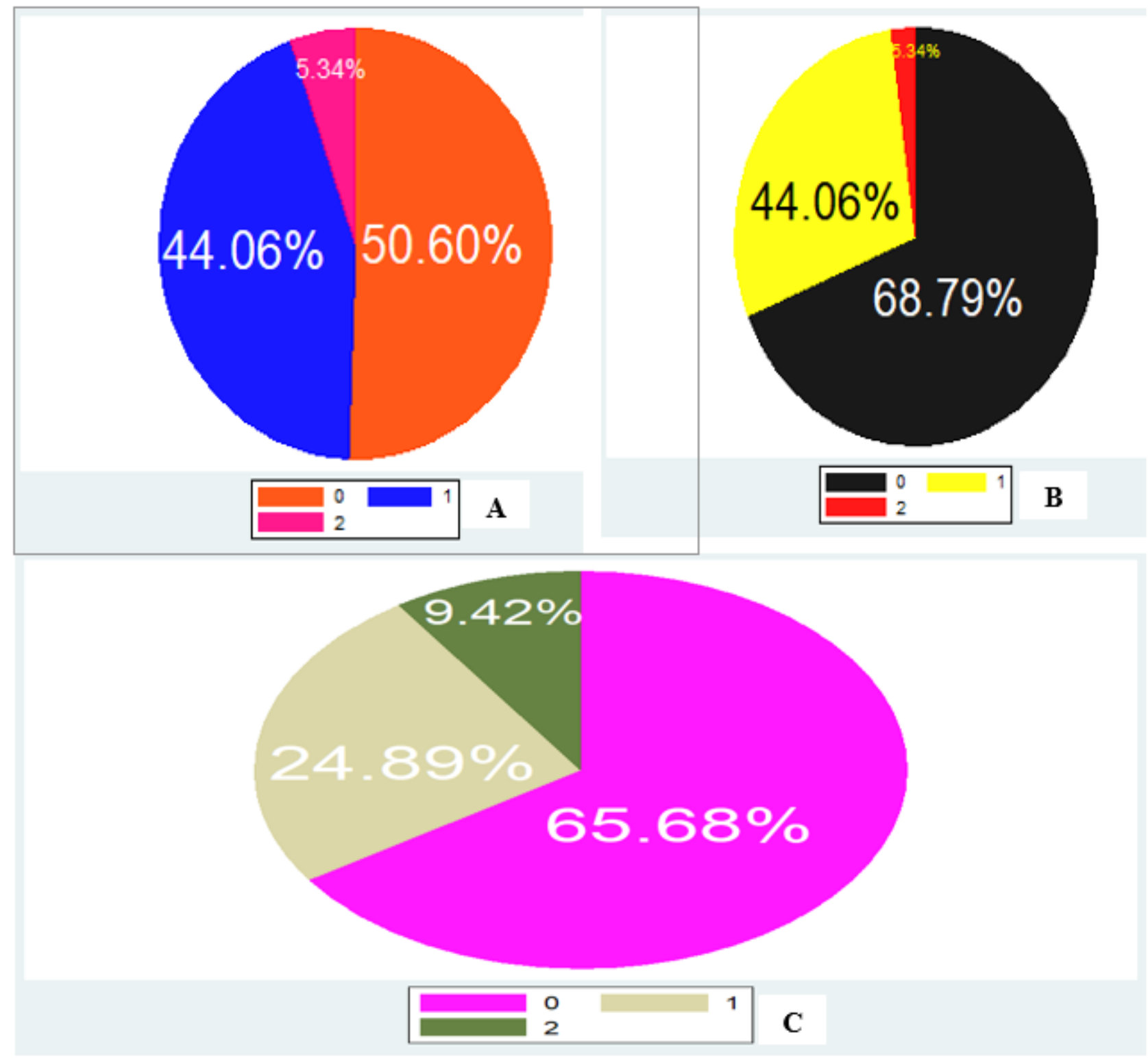

Figure 1

Fitted model for KAP towards HBV. A: Knowledge related factors; B: Attitude related factors; C: Practice related factors

\section{Supplementary Files}

This is a list of supplementary files associated with this preprint. Click to download.

- Updated.pdf 